\title{
Moçambique: das palavras escritas
}

Sueli Saraiva ${ }^{1}$

(Universidade de São Paulo)

s professores e estudantes brasileiros conhecem ou pelo menos já ouviram falar do projeto editorial de livros de bolso chamado "Coleção Primeiros Passos". O objetivo dessa coleção é iniciar o público leitor em diversos domínios do conhecimento, entre eles a literatura, sendo “o que é...?” a emblemática expressão que inicia os mais de trezentos títulos da coleção. A seqüência da frase apresenta o assunto que será de forma sucinta e didática tratado no pequeno livro. Os temas variam desde "O que é materialismo dialético?" ou "O que é português brasileiro?" ou o mais específico "O que é literatura infantil?” e por aí vai. Essa aparentemente simples pergunta, "o que é...?”, aparece de modo muito mais instigador do que didático na obra Moçambique: das palavras escritas.

Trata-se de um trabalho primorosamente organizado por Margarida Calafate Ribeiro e Maria Paula Meneses, publicado pela editora portuguesa Afrontamento (Porto, 2008). Conforme demonstram os catorze ensaios que compõem a obra, o estudioso da literatura que se propusesse no momento a responder ao hipotético título "O que é literatura moçambicana?" encontraria pela frente uma série de desafios quiçá intransponíveis. Obviamente a obra organizada por Ribeiro e Meneses é muito mais complexa e suscita questões que estão além dos "primeiros passos" no estudo da literatura moçambicana; ao contrário, os ensaios escritos por renomados críticos literários, escritores e demais estudiosos da cultura moçambicana, além das organizadoras, propõem um estudo aprofundado e mesmo desafiador neste campo que tem se mostrado escorregadio até mesmo para aqueles que perseguem incansavelmente o assunto.

1 Doutoranda em Estudos Comparados de Literaturas de Língua Portuguesa na Universidade de São Paulo (USP). 
Neste sentido, as organizadoras avisam que a obra não tem a pretensão de explicar ou meramente responder à pergunta "o que é a literatura moçambicana?”. Antes, os leitores são convidados a debaterem com os ensaístas os desafios da crítica num contexto literário forjado sob a interferência decisiva de três momentos históricos: "o colonialismo tardio e as lutas nacionalistas; a independência e o ciclo socialista; e a ambigüidade do tempo presente", conforme muito bem sinalizado no texto de abertura, "Cartografias Literárias Incertas", assinado por Ribeiro e Meneses. As "incertezas" refletidas no mapa literário moçambicano coincidiriam com as próprias incertezas que a história tem legado às gentes que ocupam milenarmente esse espaço territorial rico em diversidades lingüísticas, culturais, sociais etc.

O Estado-nação moçambicano que adentra o século XXI em lento processo de desenvolvimento, e em meio a crises sociais de várias ordens, foi "inventado" em finais do século XIX, recordam as organizadoras, naquela fatídica Conferência de Berlim entre 1884-85. Assim, ao fazer uma incursão pela história da literatura moçambicana, a presente obra também desvela as conseqüências daquele ato arbitrário que definiu as fronteiras dos domínios coloniais na África. Ocasião em que se substituiu a violência da "força da espada e da bala" pelos novos e não menos violentos paradigmas coloniais: legislação leonina, educação formal em português para os africanos assimilados, ocultação da história africana e reescrita de identidades. Enfim, a contínua configuração do palimpsesto histórico-cultural que desde o século XV se impõe às terras africanas.

No entanto, o advento da destituição do poder colonial e promulgação da independência moçambicana, em 1975, não iniciou o novo capítulo de liberdade e igualdade que estava no horizonte utópico de sua elite literária, a qual antes e depois do processo de independência alistou-se ao projeto de "moçambicanidade" e armou-se de verso e prosa, e algumas vezes de armas mesmo, em defesa de mudanças efetivas, contrárias à ideologia colonialista. A literatura que floresceu nesse contexto pregava sobretudo a retirada do véu que encobria a face ainda legítima dos povos moçambicanos, a sua identidade. Diante do processo alterado, mas não encerrado, de descolonização social e mesmo intelectual - como Fátima Mendonça irá demonstrar nesta obra - a literatura mantém sua marcha em busca de apreender, elaborar e refletir um estado de coisas ainda circunscrito em signos de neocolonialismos. 
Das palavras escritas é um subtítulo auto-explicativo, mas digno de um breve comentário, pois retoma a questão sempre pertinente da oralidade e escrita nas literaturas africanas. Nele está implícito que há um inverso das "palavras escritas", isto é, as "palavras faladas": um dos pontos fundamentais em torno da questão "o que é a literatura moçambicana?" que a obra suscita. Em outras palavras, o que significa um projeto literário escrito em português que não contempla $90 \%$ de sua sociedade (pouco mais de $10 \%$ da população tem o português como língua materna, as autoras recordam). Ora, Moçambique e sua literatura não seriam também de "palavras faladas" da literatura oral? Ou ainda dos escritos feitos em línguas como o árabe, o ki-swabilli, que ali chegaram antes mesmo do colonizador europeu?

Estas são algumas das reflexões que os ensaios trazem para o debate sobre a história, a cultura e a literatura desse mosaico de povos e saberes que é Moçambique. Seus autores são de nacionalidades diversas (moçambicana, brasileira, portuguesa, britânica) e apresentam temas e propostas críticas diversos. Esse grupo multicultural de pensadores vem ao encontro, portanto, da plurivocalidade cara à literatura moçambicana; uma plurivocalidade que ganha corpo nas páginas de Mia Couto, Ungulani Ba Ka Khosa, José Craveirinha, Luis Carlos Patraquim, Lilía Momplé e muitos outros, e "coloca sob suspeita as rígidas fronteiras dos territórios geográficos e culturais com que muitos insistem em espartilhar Moçambique" (p. 13).

Abrindo a série de ensaios de Moçambique: Das palavras escritas, a moçambicana Fátima Mendonça aborda o tema "Literaturas Emergentes, Identidades e Cânone", chamando a atenção para os limites das teorizações, que podem representar de maneira totalizante sistemas literários que emergiram, por exemplo, de situações coloniais, sem levar em conta a conjuntura histórica em que se desenvolveram. Deste modo, como definir o cânone da literatura moçambicana? Na seqüência, o também moçambicano Francisco Noa retoma a questão da produção e do cânone literário moçambicano em "Literatura Moçambicana: os trilhos e as margens". Noa analisa a literatura moçambicana para frente e para trás, para o passado e o futuro, mas também para os lados, para os demais sistemas literários com os quais ela dialoga. O crítico argumenta que o "sistema semiótico, apesar de autônomo, mantém uma relação dinâmica e estruturante não só com outros sistemas semióticos, mas também com o contexto histórico e social em que as obras vão surgindo” (p. 35). Ain- 
da no quesito teoria literária e cânone, Ana Mafalda Leite, revisita a história da formação da literatura moçambicana em "Tópicos para uma História da Literatura Moçambicana", partindo de premissas de Antonio Candido, como a de que "cada literatura requer tratamento peculiar, em virtude dos seus problemas específicos, ou da relação que mantém com as outras" (p. 47), ou a teoria do triângulo "autor-obra-público". Ana Mafalda faz um exercício de crítica literária africana à luz das teorias de Candido e conclui, por exemplo, que "os períodos anteriores ao século XX, naquele território [Moçambique], não configuram ainda uma literatura, enquadrada na concepção triangular proposta pelo ensaísta brasileiro" (p. 48).

Seguem-se visões que, ao fazerem leituras mais dirigidas sobre obras e períodos literários em Moçambique, vêm ilustrar as digressões teóricas dos três ensaístas anteriores. Assim comparecem ao debate Maria-Benedita Basto, com "Relendo a literatura moçambicana dos anos 80"; Phillip Rothwell, com "Os jogos de gênero em três contos de Mia Couto"; David Brookshaw vai à janela voltada para o Oriente e discorre sobre "Indianos e o Índico: o pós-colonialismo transoceânico e internacional em O outro pé da sereia, de Mia Couto"; em "Revolução e identidades nacionais em Moçambique: diálogos (in)confessados", André Cristiano José retoma a discussão das identidades, tratada por Fátima Mendonça no primeiro texto.

O debate sobre a literatura moçambicana não poderia abster-se do tema do feminino, considerando que uma das vozes mais proeminentes de sua literatura é Paulina Chiziane, autora que não se abstém de abordar o universo feminino em Moçambique. É justamente a obra dessa autora que Hilary Owen se dedica no ensaio "A língua da serpente - A auto-etnografia no feminino em Balada de Amor ao Vento de Paulina Chiziane". Outro ensaio dedicado àquela que é considerada a primeira mulher romancista de Moçambique vem de Silvio Renato Jorge, que apresenta mais uma faceta do corpus literário moçambicano, o já possível comparatismo entre duas escritoras moçambicanas com o ensaio "Entre guerras e narrativas: percursos da escrita de Paulina Chiziane e Lúlia Momplé".

Rita Chaves e Alice Cruz voltam-se para a obra do historiador e escritor João Paulo Borges Coelho, com ensaios que se complementam e revelam o caminho da produção literária moçambicana indissociável de sua história e da biografia de seus escritores. Em "Notas sobre a Ficção e a História em João Paulo Borges 
Coelho", Rita Chaves faz um retrato do percurso literário e das estratégias narrativas do historiador que, em pouco mais de seis anos de estréia no universo da ficção, tornou-se um dos mais sensíveis captadores da realidade moçambicana contemporânea, de modo a representá-la sob pontos de vista que expandem a "territorialidade literária do país" (p. 188). Também abordando a história e a literatura, Alice Cruz elege para análise uma das obras desse autor no texto intitulado "Entre a evidência e a verdade nos interstícios da experiência e da memória com As duas sombras do rio, de João Paulo Borges Coelho". Ao analisar a construção dessa narrativa, com destaque para as personagens, a ensaísta destaca a forma alegórica e poética com que o romancista aborda a memória e a história para tratar das ambigüidades sociais do presente.

O último trio de ensaístas é composto pelos escritores moçambicanos, entre eles o próprio João Paulo Borges Coelho, juntamente com o poeta Luís Carlos Patraquim e Nelson Saúte. Em "Da poesia como desencontro com a História", Patraquim apresenta o testemunho poético de seus ilustres pares, José Craveirinha e Rui Knopfli, e o diálogo contestador que suas poéticas travaram com a história. A relação entre a literatura e experiência pessoal nos conturbados anos de 1980 em Moçambique é relatada por Nelson Saúte em "Escrever e (sobre) viver em Moçambique", um texto autobiográfico que confirma a importância das experiências pessoais na configuração do quadro literário moçambicano.

Por fim, João Paulo Borges Coelho, na qualidade de escritor e historiador, fecha este ciclo de debates com o texto "Escrita acadêmica, escrita literária", título pelo qual o autor fala de sua própria experiência de acadêmico e literato, mas também retoma indiretamente as questões abordadas nos textos anteriores, os quais, formulados tanto por literatos quanto por acadêmicos tratam de um mesmo e complexo assunto: a literatura moçambicana. Ao refletir sobre os elementos que aproximam ou distinguem as duas formas de reflexão sobre uma realidade e sua representação em "palavras escritas", João Paulo conclui que "seja a razão da escrita acadêmica ou a estética da escrita literária, por detrás de ambas está a questão da nossa responsabilidade enquanto produtores quer de escrita acadêmica, quer de escrita literária” (p. 235).

Moçambique: das palavras escritas, portanto, indica que tão importante, ou até mais importante, do que responder a pergunta "o que é literatura moçambicana?” seria talvez outra pergunta: como é a literatura moçambicana? 